\title{
The SRK regression formula in calculating the dioptric power of intraocular lenses
}

\author{
JOSE L. MENEZO, VICENTE CHAQUES, AND MIGUEL HARTO \\ From the Department of Ophthalmology, Postgraduate Medical School, La Fe Medical Centre, Valencia, Spain
}

SUMMARY One hundred and seventy one eyes with intraocular lenses were studied to compare the predictive accuracy of the Fyodorov and Van der Heijde theoretical formulae of the SandersRetzlaff-Kraff (SRK) regression formula. The SRK regression formula was the most accurate. Our personal calculations of the A constants of this formula are given for several types of implants and manufacturers.

Calculation of the dioptric power of intraocular lenses (IOL) started with Ridley, ${ }^{1}$ who, on implanting an IOL for the first time, committed an error and left the patient highly myopic $\left(-18 \mathrm{sph},-6 \mathrm{cyl} \times 120^{\circ}\right)$.

Fyodorov and Kolinko ${ }^{2}$ presented a theoretical formula based on geometrical optics, using keratometry and ecography. Colenbrander, ${ }^{3}$ Thijssen, ${ }^{4}$ Van der Heijde, ${ }^{5}$ and Binkhorst ${ }^{6}$ also developed theoretical formulae based on geometrical optics, using theoretical constants in reference to schematic eyes.

Although apparently different, all these formulae are in fact identical and differ only in terms of small correctional factors. They may all be algebraically transformed thus ${ }^{7}$ :

$$
P=\frac{N}{L-C}-\frac{N K}{N-K C}
$$

where: $\mathrm{P}=$ dioptric power of the IOL for assuring emmetropia, $\mathrm{N}=$ refractive index of vitrcous and aqueous humour, $\mathrm{C}=\mathrm{cstimated}$ postoperative anterior chamber $(A C)$ depth in $\mathrm{mm}, \mathrm{L}=$ anteropostcrior length of cyc in $\mathrm{mm}, \mathrm{K}=$ corncal dioptric power.

Recently Sanders, Retzlaff, and Kraff ${ }^{8-10}$ studied a series of more than 2500 by means of a regression analysis involving the search for a mathematical function that best interrelates a number of variables. They found that the dioptric power of the IOL for assuring emmetropia fundamentally depends on the axial length of the eye and the corneal dioptric power. On the other hand the postoperative depth of the AC and the refractive indices of the aqueous and vitreous humours bear no significant influence. In this way Correspondence to Dr J. L. Menczo, Departamento de Oftalmologia, Ciudad Sanitaria La Fc, Av Campanar 21, Valencia-9, Spain. they developed and perfected a simplified regression formula, coming to the same conclusions from completely different sources of data. This gave rise to the SRK formula.

We have studied 171 patients with intraocular implants from a large variety of models and manufacturers. The final visual acuity (VA) was equal or greater than 20/40 in all cases. All implants were carried out by the same surgeon. The axial length of the eye was measured prior to the operation with a Systems Inc. Ophthalmoscan model 100 sonometric echograph. The corneal dioptric power and its curvature radii were registered in its principal meridians with a carefully calibrated Haag-Streit ophthalmometer. The anterior chamber depth and the corneal thickness were measured with the pachymeter of the Haag-Streit slit-lamp. The postoperative ophthalmometric data as well as the final VA were recorded on average 9 months after surgery.

The dioptric power of the IOL was calculated according to the following formulae:

$$
\begin{aligned}
& \text { Fyodorov: } P=\frac{N-L K}{(L-C)\left(1-\frac{C K}{N}\right)} \\
& \text { Van der Heijde }(V D H): \\
& P=\frac{N}{L-C}-\frac{1}{\left(\frac{1}{K}-\frac{C}{N}\right)} \\
& \text { SRK: } P=A-2.5 L-0.9 K
\end{aligned}
$$

where $P, N, L, K$, and $C$ are the parameters mentioned above and $A$ is a constant derived for cach type of lens and manufacturer.

In the first calculation we considered the constant $A$ as indicated by Sanders, Retzlaff, and Kraff in their 

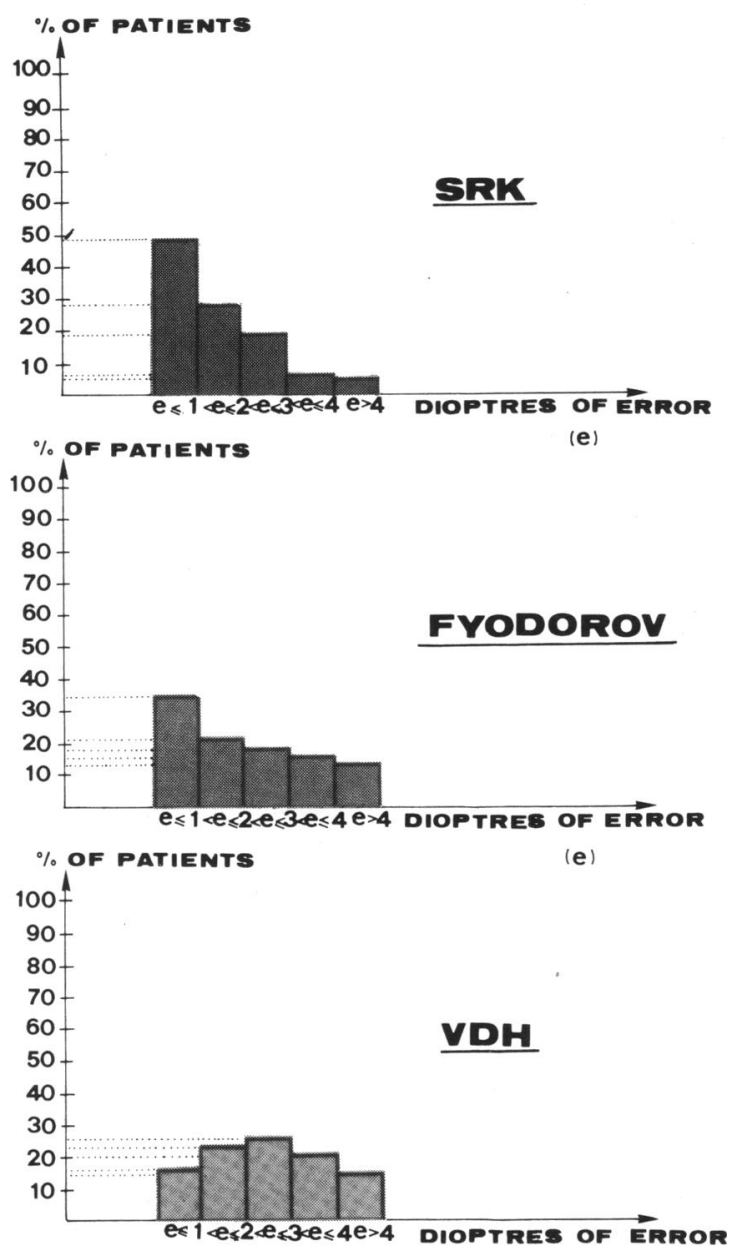

Fig. 1 Percentage distribution of the number of cases according to residual error (e) and calculation formula.

manual. ${ }^{7}$ In the event of any of them not having been published, we made use of an assumed constant $A$.

After the operation, and knowing the dioptric power of the actual implanted lens as well as the additional postoperative correction by which the maximum VA is obtained, we calculated the dioptric power of the ideal lens that should have been implanted in order to assure emmetropia. This calculation was carried out with the following formula:

$$
P_{c}=P_{\text {real }}+1 \cdot 5 R
$$

where: $P_{c}=$ power of the ideal lens that would have assured emmetropia, $P_{\text {re:al }}=$ power of the implanted lens, and $R=$ spherical equivalent of the additional postoperative refraction.

Subsequently we found the difference or error existing in each case between the power of the ideal IOL for

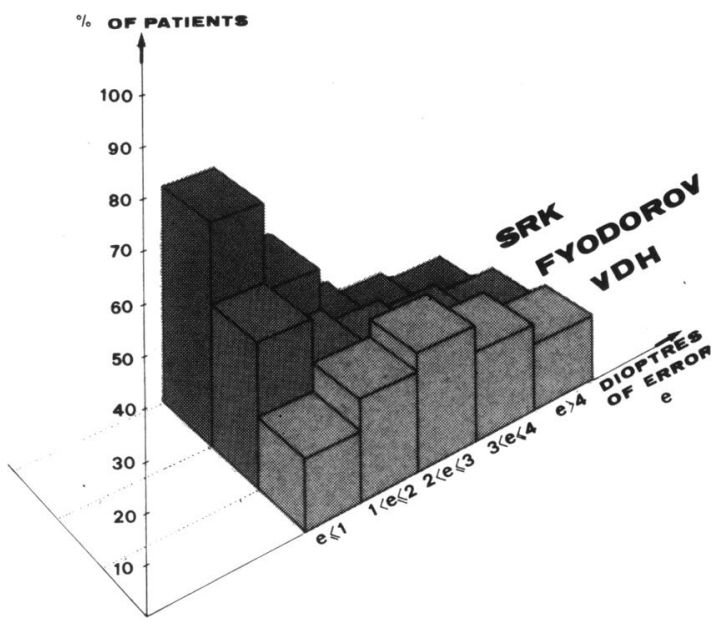

Fig. 2 Percentage distribution of the number of cases according to residual error (e) and calculation formula.

assuring emmetropia and that calculated for each one of the formulas.

The results obtained on analysing these differences or errors were as follows:

$\begin{array}{lll} & \text { Mean } & S D \\ \text { Fyodorov formula } & 2 \cdot 84 & 1.80 \\ \text { VDH formula } & 3.21 & 1.91 \\ \text { SRK formula } & 2.18 & 1.43\end{array}$

The percentage distribution of the number of cases according to the residual error (e) and the calculation formula for all 171 intraocular lenses was as follows (Figs. 1 and 2):

$\begin{array}{llllcr} & e \leqslant l & l<e \leqslant 2 & 2<e \leqslant 3 & 3<e \leqslant 4 & 4<e \\ \text { SRK } & 48.45 & 28.64 & 10 \cdot 90 & 6.36 & 5.65 \\ \text { Fyodorov } & 3(0.44 & 21.62 & 18.36 & 15.73 & 13.85 \\ \text { VDH } & 16.25 & 22.65 & 26.48 & 20.31 & 14.31\end{array}$

The superiority of the SRK regression formula over the 'classical' theoretical formulae has been shown in different reports by Sanders et al. ${ }^{8-11} \mathrm{We}$ have made the same observation in our own series.

These authors point out that the constant $A$ of the SRK formula must be individualised for each type of lens and manufacturer if we wish to assure maximum precision in calculating the dioptric power of the IOL.

What is more, even for the same type of lens and manufacturer they observed small differences according to the surgeon in charge of implanting a given series of intraocular lenses. ${ }^{7}$ In view of this, Sanders, Retzlaff, and Kraff advise calculating personal A constants and comparing them with those published.

In the 171 eyes considered here we implanted an 
Table 1 A constants for each type of lens and manufacturer

\begin{tabular}{|c|c|c|c|}
\hline Type of lens & Manufacturer & $\begin{array}{l}\text { A } \\
\text { (published } \\
\text { or assumed) }\end{array}$ & $\begin{array}{l}A^{\prime} \\
\text { (ours) }\end{array}$ \\
\hline Choice Mark IX & Rayner & $116 \cdot 0$ & $115 \cdot 1$ \\
\hline Miniflex & Cilco & $115 \cdot 3$ & $114 \cdot 7$ \\
\hline Optiflex & Cilco & $115 \cdot 3$ & $114 \cdot 8$ \\
\hline Fyodorov-Sputnik & Medexport URSS & $115 \cdot 6$ & $114 \cdot 8$ \\
\hline Worst Medallion & Mcdical Workshop & $115 \cdot 6$ & $113 \cdot 1$ \\
\hline \multicolumn{4}{|l|}{ Binkhorst 2-Loop } \\
\hline Iridocapsular & Morcher & $115 \cdot 0$ & $113 \cdot 8$ \\
\hline \multicolumn{4}{|l|}{ Binkhorst 4-Loop } \\
\hline Irisclip & Morcher & $115 \cdot 1)$ & $113 \cdot 2$ \\
\hline Simcoe & Cilco & $116 \cdot 6$ & $115 \cdot()$ \\
\hline Simcoc II & Cilco & $116 \cdot 6$ & $115 \cdot 2$ \\
\hline Pearce Tripod & Rayner & $117 \cdot 6$ & $116 \cdot 2$ \\
\hline Pearce Tripod & Cilco & $117 \cdot 6$ & $116 \cdot 1$ \\
\hline Kratz J-Loop KR-I & Cilco & $116 \cdot 2$ & $115 \cdot 0$ \\
\hline
\end{tabular}

IOL calculated by the SRK formula and using the constants A (published or assumed) as indicated in Table 1 . We then determined $P_{c}$ and the difference between $P_{c}$ and $P_{\text {SRK }}$ (dioptric power calculated by the SRK formula). Subsequently we tried to calculate the constant $\mathrm{A}$ which in each case we would have had to use in order to make $P_{\text {SRK }}$ coincide with $P_{c}$. This particular constant $\mathrm{A}$ was for each case referred as $\mathrm{A}^{\prime}$.

In order to determine the $\mathrm{A}^{\prime}$ corresponding to each case we algebraically added the value of $\left(P_{c}-P_{S R K}\right)$ to A. We then calculated the arithmetical mean of these
$\mathrm{A}^{\prime}$ values for not fewer than 10 cases of a given type of lens and manufacturer. The result was our own constant $\mathrm{A}$ for that particular lens and manufacturer (Table 1).

\section{References}

I Ridley $\mathrm{H}$. Intra-ocular acrylic lenses. A recent development in the surgery of cataract. Br J Ophthalmol 1952; 36: 113-22.

2 Fyodorov SN, Kolinko AI. Estimation of optical power of intraocular lens. Vesin Oftalmol 1967; 80: 27-31.

3 Colenbrander MD. Calculation of the power of an iris clip lens for distance vision. BrJ Ophthalmol 1973; 57: 735-40.

4 Thijssen JM. The emmetropic and the isciconic implant lens: computer calculation of the refractive power and its accuracy. Ophthalmologica 1975; 171: 467-86.

5 Van der Heijde GL. A nomogram for calculating the power of the prepupillary lens in the aphakic eye. Bibl Ophthalmol 1975; 83: 273-5.

6 Binkhorst RD. The optical design of intraocular lens implants. Ophthalmic Surg 1975; 6: 17-31.

7 Retzlaff J. Sanders D, Kraff M. A manual of implant power calculation. Oregon: Medford, 1982.

8 Retzlaff J. A new intraocular lens calculation formula. Am IntraOcular Implant Soc J 1980; 6: 148-52.

9 Sanders D, Kraff M. Improvement of intraocular lens power calculation using empirical data. Am Intra-Ocular Implant Soc $J$ 1980): 6: $148-52$.

10) Retzlaff J. Posterior chamber implant power calculation: regression formulas. Am Intra-Ocular Implant Soc J 1980; 6: 268-70.

11 Sanders D. Retzlaff J, Kraff M, et al. Comparison of accuracy of Binkhorst. Colenbrander and SRK implant power prediction formulas. Am Intra-Ocular Implant Soc J 1981; 7: 337-40. 